\title{
Management of a Dual-Bus AC+DC Microgrid based on a Wind Turbine with Double Stator Induction Generator
}

\author{
MARCELO G. CENDOYA ${ }^{1}$, JUAN I. TALPONE ${ }^{1,2}$, PAUL F. PULESTON ${ }^{1}$, \\ JOSE A. BARRADO-RODRIGO ${ }^{3}$, LUIS MARTINEZ-SALAMERO ${ }^{3}$, PEDRO E. BATTAIOTTO $^{1}$ \\ ${ }^{1}$ Instituto de Investigaciones en Electrónica, Control y Procesamiento de Señales (LEICI), \\ Departamento de Electrotecnia, Facultad de Ingeniería, \\ Universidad Nacional de La Plata. CONICET. Asoc. CICPBA. \\ C.C. 91, 1900, La Plata, Buenos Aires, \\ ARGENTINA
}

${ }^{2}$ Wallbox Chargers, S.L.,

Carrer Josep Ros i Ros, 21, 08740 Sant Andreu de la Barca, Barcelona, SPAIN

\author{
${ }^{3}$ Grup d'Automàtica i Electrònica Industrial (GAEI), \\ Departament d'Enginyeria Electrònica Elèctrica i Automàtica (DEEEA), \\ Escola Tècnica Superior d'Enginyeria (ETSE), \\ Universitat Rovira i Virgili, \\ Països Catalans, 26, 43007, Tarragona, \\ SPAIN
}

\begin{abstract}
The topology and management of a sustainable dual-bus, AC and DC, microgrid designed to operate connected to a weak grid is presented. AC+DC hybrid microgrids are a robust and cost-competitive solution for poorly connected areas, as can be found in rural or island electrification. The versatile microgrid proposed in this work is developed around a wind turbine based on a particular induction generator with double stator winding and squirrel cage rotor (DWIG).

This singular generator is especially suitable for a combined AC+DC coupled microgrid application. One of its stator windings is coupled to the DC bus via a controlled AC/DC converter. The other is directly connected to the AC bus, only during the periods of abundant wind resource. The DWIG is complemented with photovoltaic panels and a hybrid energy storage system, comprising flow batteries assisted by supercapacitors, which converge to the DC Bus. The DC bus exchanges power with the AC bus through an interlinking inverter. The article describes the topology and details the operation of its Supervisory Control system, which gives rise to the five operating modes of the proposed AC+DC DWIG based microgrid. Its performance under different generation conditions and load regimes is thoroughly assessed by simulation.
\end{abstract}

Keywords: - Hybrid microgrid; Renewable generation; DWIG; Flow Battery; Supercapacitor; Weak grid.

Received: April 30, 2021. Revised: November 15, 2021. Accepted: December 6, 2021. Published: December 22, 2021.

\section{Introduction}

Nowadays, most of the energy used for transportation and a significant part of that used for stationary activities comes from fossil fuels. It is true that, during the last century, the use of this type of fuel has allowed the development of technological, has increased productivity, and has improved the living standard in many areas of the world. However, this situation is no longer sustainable today. Fossil fuels not only are nonrenewable energy resources, but significantly degrades the environment, lasting their damaging effects for many years. In addition, from a strategic viewpoint, many countries that require the continuous use of this type of fuels, become severely dependent on those that can provide them. Considering this situation, from the 90s on, actions were undertaken in different parts of the world to 
diversify primary energy sources, incorporating non-fossil alternative energies. Among these, wind and photovoltaic stand out, although research and development of other sources such as biomass, geothermal, marine and hydrogen are progressively taking place.

Another drawback inherent to traditional electricity generation plants is that they are usually far from consumption centers, requiring a complex and expensive infrastructure for the transport and distribution of energy. Consequently, in large countries with the presence of weak grids, many consumers do not have access to the appropriate electricity supply, or it is very limited in quality and power availability.

An alternative to the above paradigm, arises when the generation takes place near the points of consumption. This is known as Distributed Generation (DG) and represents one of the basis for the development of future electrical power systems. When the DG incorporates energy generation and storage systems from renewable resources, there is a Renewable Distributed Generation (RDG) system $[1][2][3][4]$. If these generation and storage structures are integrated into a small-scale power grid and operate in a coordinated manner under a Supervisory Control System (SCS), managing energy and power flows, they are called Microgrids (MG). These are frequently connected to low voltage distribution lines and close to consumption points [5]. MGs can be classified according to the type of current in the distribution bus as AC, DC, or $\mathrm{AC}+\mathrm{DC}$ hybrids (which combine the previous two) [6] [7] [8].

Contrasting to entirely AC or DC microgrids, hybrid $\mathrm{AC}+\mathrm{DC} \mathrm{MG}$ are able to integrate $\mathrm{AC}$ or $\mathrm{DC}$ sources, storage units and loads more easily, reducing the power conversion process and improving energy conversion efficiency. Additionally, they proved to be highly versatile. In these hybrid configurations the role of the Supervisory Control System is particularly relevant [9] [10].

In this framework, a dual-bus $\mathrm{AC}+\mathrm{DC}$ hybrid microgrid topology and its supervisory control strategy are proposed and analyzed in this paper. It is designed to fully exploit the features of a special type of wind turbine (WT) based on an induction generator with a squirrel cage rotor and double stator winding (DWIG) [11]. This two-windings machine maintains the robustness of the squirrel cage, while each one of the stator windings can be coupled to the AC bus and the DC bus, independently [12].
Then, in the designed MG, part of the generation system (the Control Winding of the DWIG and Photovoltaic Panels) and a hybrid energy storage module (based on a Flow Battery and Supercapacitors), are connected to the DC Bus; while the Power Winding of the DWIG and a set of loads are coupled to the AC Bus (connected to a weak grid). Both buses exchange energy through an interlinking AC/DC converter managed by the SCS. In this way, the proposed DWIG based hybrid MG topology together with the supervisory control strategy, result in a versatile and modular smallscale power system, with efficient global energy management and a moderate maintenance cost.

\section{System Description}

The proposed MG is designed to operate connected to an AC weak grid, such as can be found in rural areas or places far from the main grid. The AC+DC MG topology is schematically presented in Fig. 1.

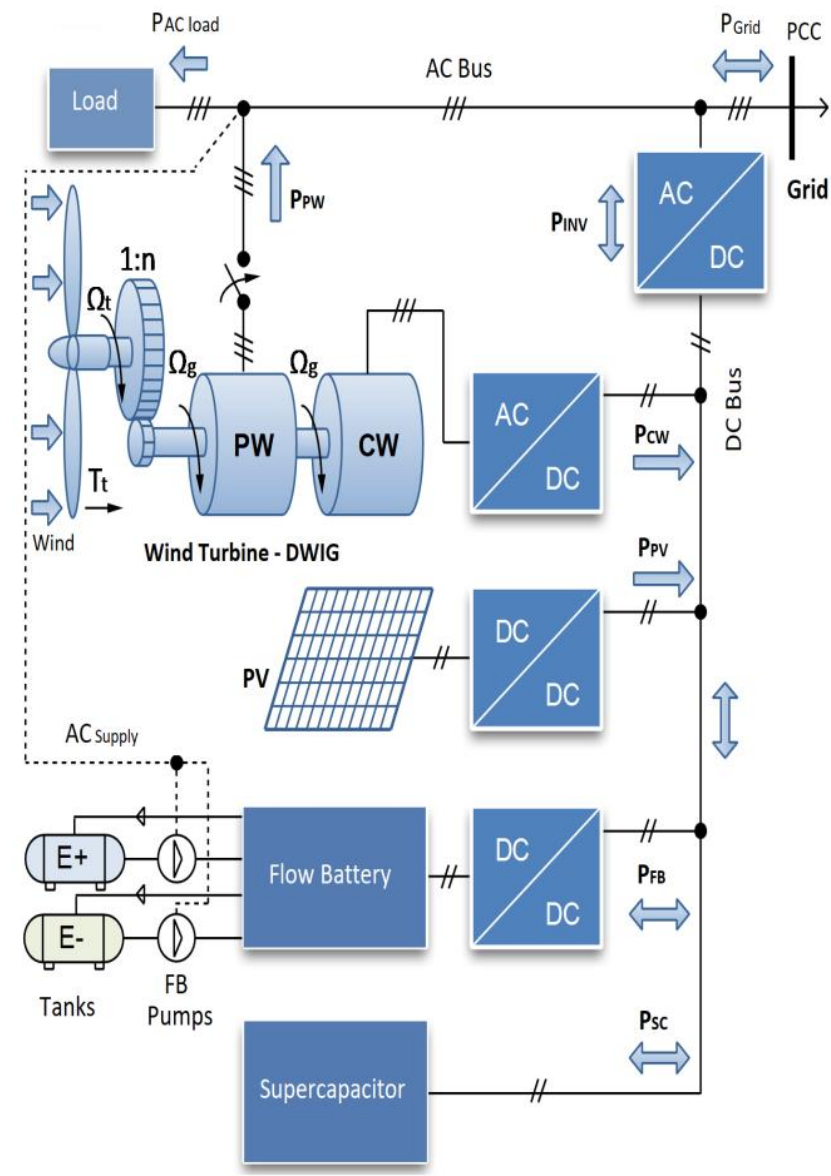

Fig. 1: Proposed AC+DC microgrid

As previously mentioned, part of the electrical generation system and the hybrid storage module, Flow Battery (FB) plus Supercapacitors (SC), share the DC Bus, which is in turn connected to the AC 
Bus through a DC/AC bidirectional converter. In particular, the FB is connected to the DC Bus by means of a bidirectional DC/DC converter, while for the photovoltaic module (PV) a unidirectional DC/DC converter is used. As it can be seen, the DWIG provides energy through its two outputs. One, with a lower power, is connected to the DC Bus through an AC/DC converter and the other, with higher power, is directly coupled to the $\mathrm{AC}$ network through a contactor.

The main characteristics of the Microgrid modules are described below.

\subsection{Power Generation Modules}

A) Wind turbine based on the DWIG (Main Energy Source). The DWIG consists of a single squirrel cage type rotor and two three-phase windings in the stator with different number of poles, to achieve a magnetic decoupling between them. This allows the DWIG to be conceived as two induction generators (IG) that share the same shaft, as represented in Fig. 1 (a detailed analysis of the machine can be found in [12]). The winding called Control Winding (CW) can transfer, through an electronic converter, up to $1 / 3$ of the nominal power of the DWIG. While the Power Winding (PW) can transfer to the AC Bus up to the remaining 2/3 of the nominal power of the generator. This structure allows the turbine to operate in such a way that, with low wind speeds, only the $\mathrm{CW}$ is used, and through an AC/DC converter, it is controlled to optimize the extraction of wind energy, implementing a strategy of Maximum Power Point Tracking (MPPT). For wind speeds in the middle range, the control objective of the $\mathrm{CW}$ turns to be constant torque, to avoid exceeding the winding current limit. Finally, for high wind speeds, the CW operates at a constant frequency and the PW winding is incorporated into the generation, connecting it directly to the AC network. A detailed description of the DWIG's areas of operation is presented in Subsection 3.1.

B) Photovoltaic module (Ancillary Energy Source). Photovoltaic solar energy proved to be a suitable complement to wind turbines as a renewable energy source in microgrids. For this reason, a photovoltaic panel module is incorporated into this Microgrid as a secondary source of energy. This PV module delivers its generated power into the DC Bus via an electronic DC/DC converter.

\subsection{Energy Storage Modules}

The objective of the energy storage system in this MG is to optimize the use of the renewable resource (wind and photovoltaic) and, at the same time, participate in the regulation of the DC Bus voltage as detailed in Subsection 3.B. In the time intervals when the combined wind and photovoltaic generation exceeds the demand, the surplus energy is stored, hence allowing the storage system to cover the energy shortfall, when the renewable resources are insufficient to satisfy local demand. To improve versatility, a hybrid storage system is proposed. It is based on Flow Batteries (FB), responsibly of handling the bulk of the storage energy. Plus, to extend their service life while improving the storage dynamics for fast power fluctuations, a bank of Supercapacitors (SC) is incorporated.

C) Flow Batteries (FB). These devices have a high energy density that allows a large storage capacity in a not very large volume. They are characterized by high charge and discharge rates, long service life, low maintenance and discharge possibility of up to $90 \%$ of the maximum state of charge (SOC). Commercial modules today are typically constructed with Vanadium Redox cells. FBs consist of two tanks, each containing electrolyte solutions that act as liquid energy carriers. Each electrolyte, driven by its respective pumps, circulates through independent cells, resulting in an exchange of ions through a common membrane and, consequently, in a current flow. In FBs, the energy storage capacity depends exclusively on the size of their tanks [13], while their power capacity is given by the area and number of the ion exchange cells in series that compose it. From this it is inferred that this battery technology presents great flexibility in sizing, as its storage capacity and power can be independently adjusted. This aspect is of particular interest for the Microgrid, given the variability of the maximum energy demand that occurs in the different rural areas or far from the main network, where it is located.

D) Supercapacitors (SC). In FBs, as in most storage systems based on electrochemical processes, the speed of change of the electrical flow is limited and manifests itself in a reduced dynamic response. Furthermore, it is particularly important to attenuate the high current fluctuations during charging and discharging to avoid deterioration of the ion exchange cells, which significantly reduces their useful life. For this purpose, a Bank of Supercapacitors (SC) is incorporated in the output terminals of the FB system (DC Bus) that allows protecting the $\mathrm{FB}$ and at the same time providing a good dynamic response in the DC Bus [14]. Thanks to the SC bank, it is possible provide or absorb the fast power peaks caused by changes in load demand or in the generation modules. 


\section{System Operating Modes}

In this section, firstly describe the different operating zones of the DWIG-based wind turbine are described and, subsequently, the operating modes of the proposed MG are analyzed in detail.

\subsection{DWIG-Based Wind Turbine Operating Zones}

The DWIG-based wind turbine plays a key role in this MG. For this reason, knowledge of its areas of operation and the resulting powers involved is essential. In Fig. 2 a diagram of the equivalent model for this generation module is shown. Both outputs of the DWIG, PW and CW, are represented by an AC and DC current source respectively. The PW corresponds to an uncontrolled source (only the connection/disconnection to the $\mathrm{AC}$ Bus can be made), while the $\mathrm{CW}$ is a controllable DC source by means the action of an AC/DC power converter associated with it. The modes of operation of the wind turbine are associated with four different areas of DWIG Torque-Speed characteristic (Fig. 3); which are directly dependent on the generator speed $\left(\Omega_{\mathrm{G}}\right)$ and implicitly on the speed of the wind. From the measurement of $\Omega_{\mathrm{G}}$, a controller determines the operating zone of the wind system and imposes the corresponding torque by acting on the converter linked to the generator's CW (schematically represented in Fig. 2), [15].

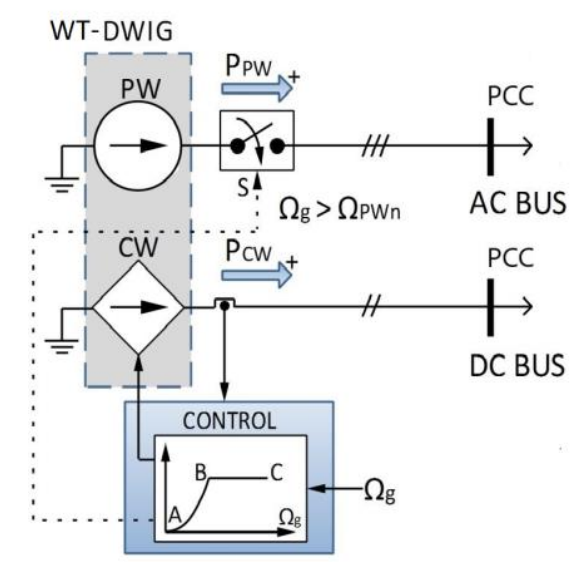

Fig. 2: Equivalent electric model of DWIG

Operation in zone $A B$. When the wind turbine is exposed to low wind speeds, the goal is to maximize the extraction of wind energy. For this reason, it was decided to use a maximum power point tracking strategy (MPPT), by means of controlling the AC/DC converter connected to $\mathrm{CW}$ of the induction generator. In this operating area, the PW remains disconnected from the AC Bus.
The wind turbine operating points of maximum power extraction are located in the torque-speed plane on a parabola given by [15]:

$$
T_{\text {opt }}(\Omega)=\frac{C_{T\left(T S R_{\text {opt }} I \frac{1}{2} p^{2} R^{5}\right.}}{T S R_{\text {opt }}^{2}} \Omega^{2}=K_{\text {oppt }} \Omega^{2}
$$

with $\Omega$ the mechanical rotational speed, $\rho$ the air density and $R$ the blades length. $C_{T}(T S R)$ is the turbine torque coefficient which is a nonlinear function of the $T S R$, where $T S R=\frac{R \Omega}{v_{w}}$ is the Tip Speed Ratio. In particular, for fixed pitch operation, there exists one single constant value, known as $T S R_{\text {opt }}$ or optimum TSR, which ensures maximum power extraction from the wind.

In Fig. 3, the points of maximum power are shown in red dashed line. The range of this zone begins at the minimum value of the turbine turning speed $\Omega_{\mathrm{A}}=\Omega_{\min }$ (corresponding to point A in Fig. 3) and ends at the rotor speed value corresponding to point B. At this point, the system reaches the rated torque value corresponding to $\mathrm{CW}$.

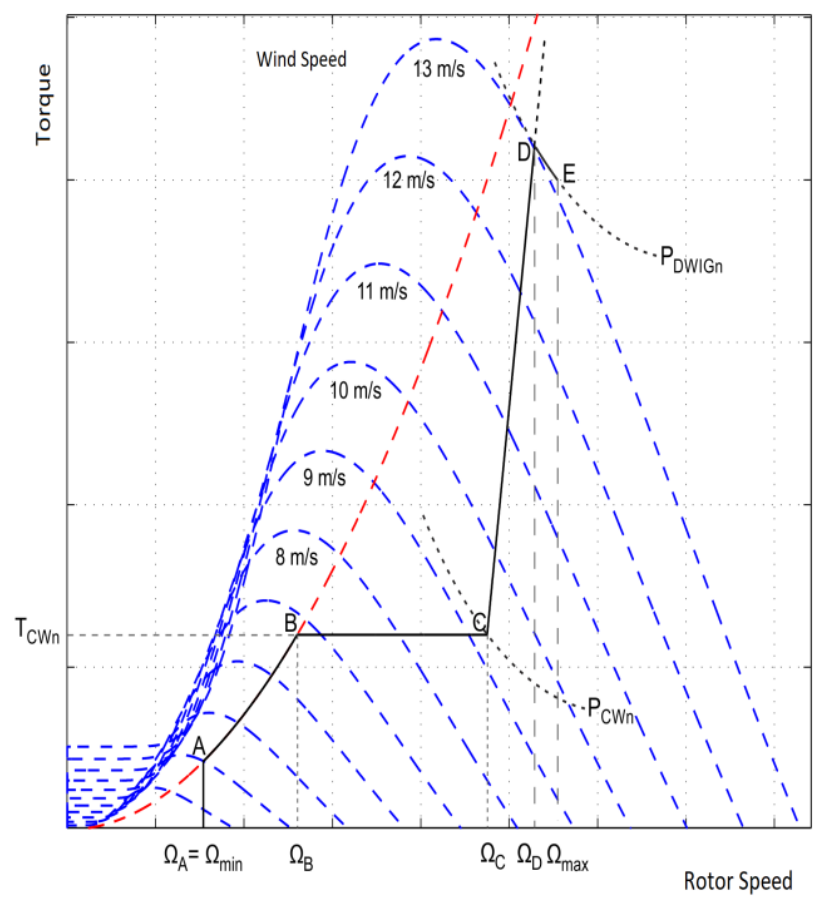

Fig. 3: Operating zones of WT-DWIG

Operation in zone $B C$. From point $\mathrm{B}$ and for higher wind speeds, the DWIG control leaves the MPPT strategy and takes into consideration that the torque value in $\mathrm{CW}$ does not exceed its rated value. This corresponds to an operation at constant torque. Since the power delivered by the generator is 
determined by the product between torque and rotor speed, in this constant torque operation (segment $\mathrm{BC}$ in Fig. 3), the power generated increases linearly with the increase in the speed of turn, as the wind speed increases. When the speed of the generator reaches $\Omega_{\mathrm{C}}$, its nominal power $\left(\mathrm{P}_{\mathrm{CWn}}\right)$ is reached in $\mathrm{CW}$. Note that, throughout this $\mathrm{BC}$ region, the $\mathrm{PW}$ continues to be disconnected from the AC Bus.

Operation in $C D$ zone. From wind speeds higher than that corresponding to point $\mathrm{C}$, the $\mathrm{CW}$ alone is not capable of processing all the wind energy, since it has already reached its maximum power $\left(\mathrm{P}_{\mathrm{CWn}}\right)$. In order to increase the energy extraction of the wind turbine, the controller enables the PW connection to the AC Bus. As this connection is made directly to the grid (according to its frequency and pole number of PW) the rotor speed of the induction generator keeps practically constant and, in turn, that of the wind turbine $\left(\Omega_{\mathrm{G}}=\Omega_{\mathrm{PWn}}=\Omega_{\mathrm{C}}\right)$. In addition to this, the $\mathrm{CW}$ continues controlled and not to exceed its nominal power. In this operating zone the $\mathrm{CW}$ transfers energy to the DC Bus, while PW injects energy to the AC Bus. This contribution is made simultaneously and in accordance with the incident wind speed in the turbine. Upon reaching point $\mathrm{D}$ (wind speed $13 \mathrm{~m} / \mathrm{s}$ in Fig. 3), PW reaches its rated power value and consequently the DWIG will also have reached the limit of its total rated power $\left(\mathrm{P}_{\text {DWIGn }}=\mathrm{P}_{\mathrm{CWn}}+\mathrm{P}_{\mathrm{PWn}}\right)$.

Operation above point $D$. When the wind speed exceeds that corresponding to point $\mathrm{D}$, overloading of the generator should be avoided $\left(\mathrm{P}_{\mathrm{DWIG}}>\mathrm{P}_{\mathrm{DWIG}}\right)$. It is assumed the existence of a mechanism for limiting power in the wind turbine, such as a system for controlling the pitch of the blades. It ensures the power limit to the $P_{\text {DwIGn }}$ value (indicated with a dotted line passing through Point D, in Fig. 3).

\subsection{Microgrid Operation Modes}

The proposed Supervisory Control System (SCS) is responsible of controlling the operation of the interlinking inverter and the loads, in order to coordinate an adequate power flow between generation, storage, loads and the weak AC grid.

An equivalent electrical model, that schematizes the topology represented in Fig. 1, is presented in Fig. 4 in order to facilitate the understanding of the proposed modes of operation. It is conceived with the assumption that the voltages on the DC and AC buses are fixed values, which allows analyzing the power flow considering only the current flow. The Inverter that links the DC Interconnection Bus with the AC Distribution Bus, is modeled as a bidirectional current source and manages the power exchange between both buses. It is operated by the SCS for different control purposes and is capable of handling the full rated load power (worst condition). Regarding the Storage Module (Flow Battery FB), it has been modeled as a controlled bidirectional current source. The power exchange between the FB and the DC Bus is a natural consequence of the process of keeping the DC bus voltage constant, assigned to this module. The control loops that determine the regulation of the DC bus voltage $\left(\mathrm{V}_{\mathrm{DC}}\right)$ and the power flow between the DC and AC Buses, are detailed In Fig. 4. This last control loop is used by the Supervisor control system to set the corresponding Microgrid Operation Mode.

Since the main objective of the Microgrid is to supply the local load power demand through the use of energy obtained from renewable sources, the SCS will operate the microgrid reducing the power exchange with the Weak Grid to the essential minimum. In this sense, five modes have been developed for the Microgrid operation, depending on the different generation and demand conditions. The actions taken by the SCS, focused on the power exchange with the Weak Grid $\left(\mathrm{P}_{\text {Grid }}\right)$, are carried out by controlling the power flow in the Inverter (between DC Bus and AC Bus) and, eventually, modifying the power consumed by the non-essential load.

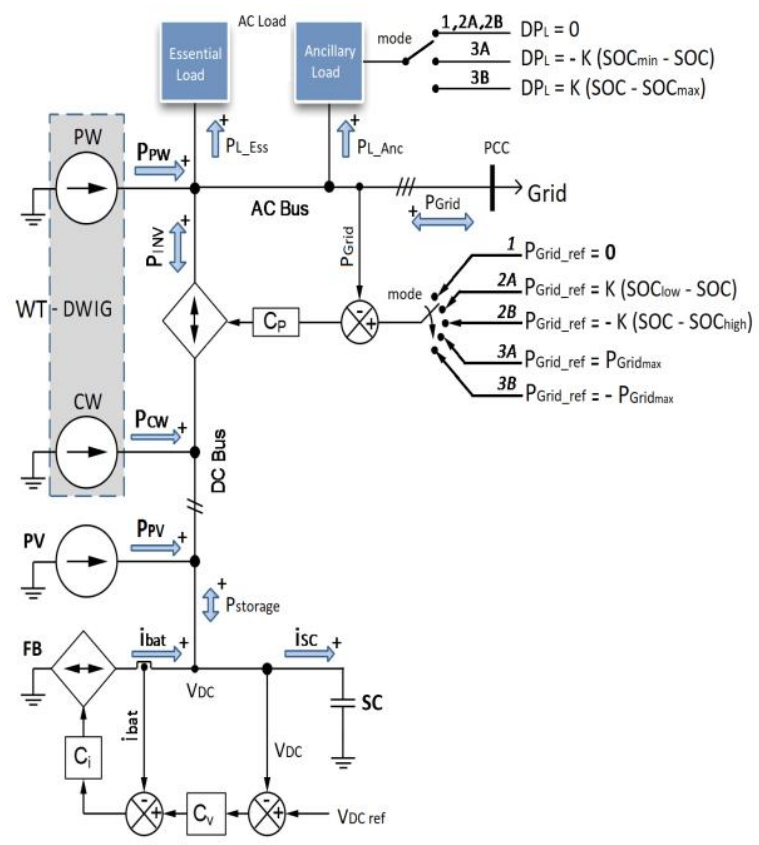

Fig. 4: Electrical equivalent model of the Microgrid. The flow diagram corresponding to the actions that the SCS executes to establish the Microgrid Operation Mode at all times is presented in Fig. 5. The corresponding decisions are made from the 
measurement of the FB's state of charge (SOC), which varies in the face of different situations of available energy and loads consumption.

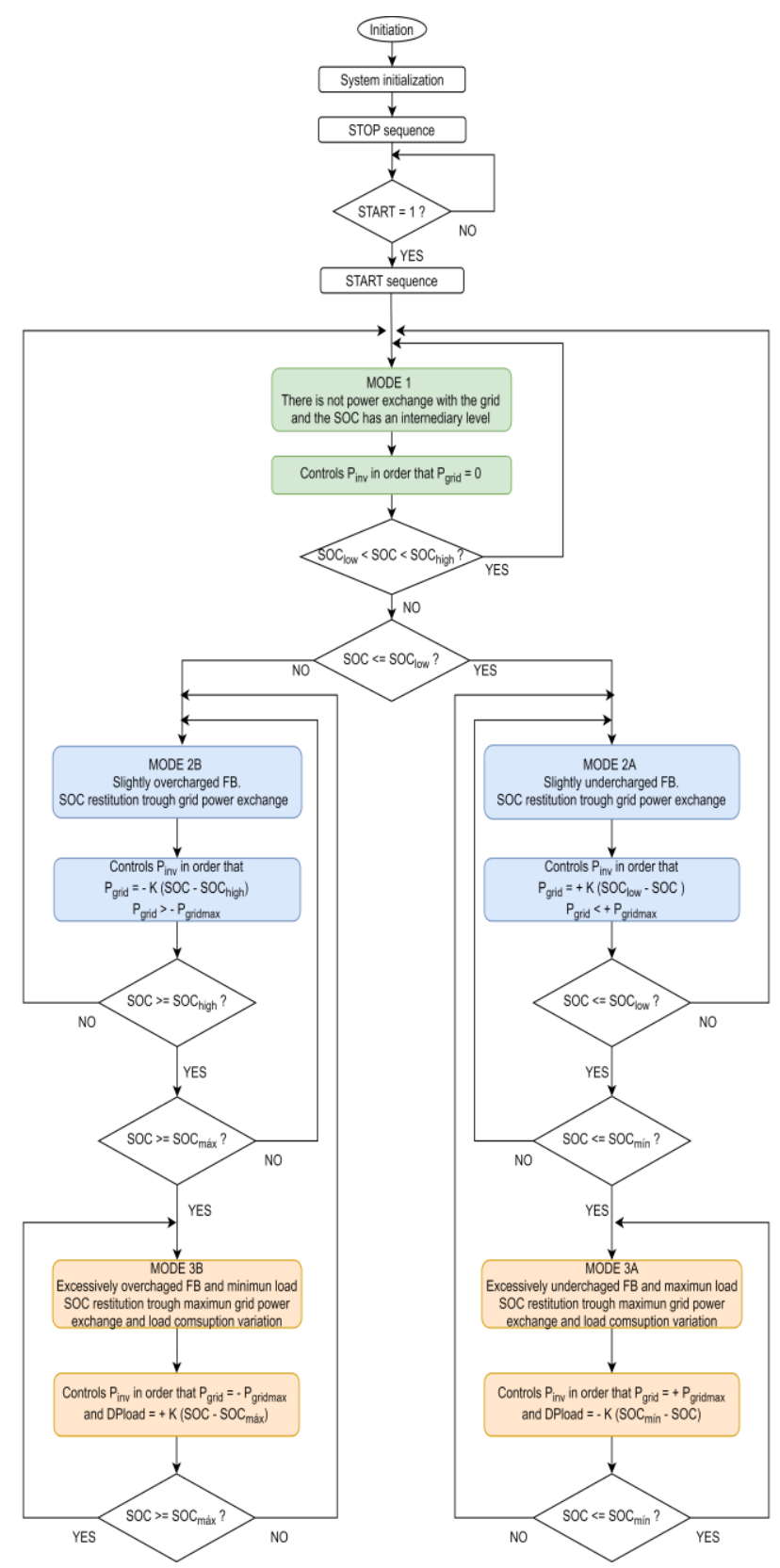

Fig. 5: Supervisory Control flow diagram.

Each of the five modes of operation are described in detail below:

Mode 1: This is the normal condition operation mode, where there is no power exchange between the Microgrid and the Weak Grid. To achieve this result, the main inverter is controlled so that $\mathrm{P}_{\text {Grid }}=0$. Thus, the whole power demanded by the Loads, (both Essential and Non-Essential) is delivered from the Microgrid by both injection routes: DC Bus through the main inverter and PW directly to the AC Bus. This means that, if the renewable resources are insufficient to supply the Loads $\left(\mathrm{P}_{\mathrm{CW}}+\mathrm{P}_{\mathrm{PV}}+\mathrm{P}_{\mathrm{PW}}<\mathrm{P}_{\mathrm{C}}\right)$, the shortfall is provided by the FB through the $\mathrm{V}_{\mathrm{DC}}$ voltage regulation process (Fig. 4). On the contrary, if there is an excessive renewable generation $\left(\mathrm{P}_{\mathrm{CW}}+\mathrm{P}_{\mathrm{PV}}+\mathrm{P}_{\mathrm{PW}}>\mathrm{P}_{\mathrm{C}}\right)$, the surplus will be absorbed by the FB through the same regulation process. Then, according to what has been established, it is true that $\mathrm{P}_{\mathrm{C}}=\mathrm{P}_{\mathrm{INV}}+\mathrm{P}_{\mathrm{PW}}$, where $\mathrm{P}_{\mathrm{INV}}=\mathrm{P}_{\mathrm{CW}}+\mathrm{P}_{\mathrm{PV}}+\mathrm{P}_{\text {Storage. }}$. The Microgrid keeps operating in Mode 1 as long as the Flow Battery has an intermediate state of charge $\left(\mathrm{SOC}_{\text {low }}<\mathrm{SOC}<\mathrm{SOC}_{\text {high }}\right)$.

Mode 2A: The microgrid enters in this operation mode when there is a shortage of renewable resources $\left(\mathrm{P}_{\mathrm{CW}}+\mathrm{P}_{\mathrm{PV}}+\mathrm{P}_{\mathrm{PW}}<\mathrm{P}_{\mathrm{C}}\right)$ to power the Loads and the Flow Battery SOC reaches a certain "low" level ( $\mathrm{SOC}<=\mathrm{SOC}_{\text {low }}$ ) because is in a discharge process by supplying the power lack. The action taken by the SCS in this operating mode is to control the Inverter so that the weak grid provides a power amount $\left(\mathrm{P}_{\text {Grid }}>0\right)$ proportional to the depth of discharge of the flow battery with respect to the "low" level:

$$
P_{\text {Grid }}=+K\left(S O C_{\text {low }}-S O C\right) ; \quad P_{\text {Grid }} \leq P_{\text {Gridmax }}
$$

In other words, an attempt is made to recover the SOC level with a power contribution from the Weak Grid, without exceeding its rated power value $\left(\mathrm{P}_{\text {Gridmax }}\right)$. The Microgrid keeps operating in Mode $2 \mathrm{~A}$ as long as the SOC of the $\mathrm{FB}$ is in the range: $\mathrm{SOC}_{\text {min }}<\mathrm{SOC}<\mathrm{SOC}_{\text {low. }}$.

Mode 3A: The Microgrid enters in this operating mode when there is a shortage of renewable resources $\left(\mathrm{P}_{\mathrm{CW}}+\mathrm{P}_{\mathrm{PV}}+\mathrm{P}_{\mathrm{PW}}<\mathrm{P}_{\mathrm{C}}\right)$ to power the Loads and, even with the maximum permissible power contribution of the weak grid $\left(\mathrm{P}_{\text {Grid }}=\mathrm{P}_{\text {Gridmax }}\right.$, action taken in Mode 2A), the FB continues in a discharging process reaching a SOC level less than or equal to a "minimum" value $\left(\mathrm{SOC}<=\mathrm{SOC}_{\mathrm{min}}\right.$ ). There are two actions taken in this operating mode: a) The Inverter continues to be controlled in the same way as in Mode 2A, so that the Weak Grid provides the maximum permissible power $\left(\mathrm{P}_{\text {Grid }}=+\mathrm{P}_{\text {Gridmax }}\right)$, b) The consumption of the nonessential loads is gradually decreased, reducing its power in proportion to the FB depth of discharge with respect to the "minimum" level:

$$
D P_{\text {Load }}=-K\left(S O C_{\text {min }}-S O C\right)
$$

The power capability of the MG modules (that should be correctly chosen through proper sizing) and the maximum admissible values of the Loads, means that in the worst case (inexistent renewable generation and maximum Essential Load 
consumption), canceling the consumption of the Non-Essential Load ensures that the Essential Load is completely fed by the Weak Grid and the FB does not continue to discharge. The Microgrid keeps operating in Mode 3A as long as the FB SOC meets: $\mathrm{SOC}<=\mathrm{SOC}_{\min }$.

Mode 2B: The Microgrid enters in this operation mode when the renewable generation is excessive $\left(\mathrm{P}_{\mathrm{CW}}+\mathrm{P}_{\mathrm{PV}}+\mathrm{P}_{\mathrm{PW}}>\mathrm{P}_{\mathrm{C}}\right)$ to power the Load, and the FB (that is in a charging process by absorbing the surplus) is slightly overcharged reaching its SOC a level equal to or higher at a certain "high" level (SOC $>=\mathrm{SOC}_{\text {high }}$ ). The action taken by the SCS in this operating mode is to control the Inverter in such a way that some power is injected into the Weak Grid $\left(\mathrm{P}_{\text {Grid }}<0\right)$, whose amount is proportional to the FB overcharge (measured with respect to the "high" level of SOC):

$$
P_{\text {Grid }}=-K\left(S O C-S O C_{\text {aig口 }}\right) ; P_{\text {Grid }} \geq-P_{\text {Gridmax }}
$$

In other words, an attempt is made to lower the SOC level by injecting power into the Weak grid, without exceeding its nominal power value $\left(\mathrm{P}_{\text {Gridmax }}\right)$. The Microgrid keeps operating in Mode 2A as long as the $\mathrm{SOC}$ of the $\mathrm{FB}$ is in the range: $\mathrm{SOC}_{\text {high }}>\mathrm{SOC}>\mathrm{SOC}_{\max }$.

Mode 3B: The Microgrid enters in this operation mode when the renewable generation is excessive $\left(\mathrm{P}_{\mathrm{CW}}+\mathrm{P}_{\mathrm{PV}}+\mathrm{P}_{\mathrm{PW}}>\mathrm{P}_{\mathrm{C}}\right)$ to feed the Loads and, even with the maximum permissible power injection to the Weak Grid $\left(\mathrm{P}_{\text {Grid }}=-\mathrm{P}_{\text {Gridmax }}\right.$, action taken in Mode 2B), the FB continues an overcharging process reaching a SOC level greater than or equal to a "maximum" level (SOC $>=\mathrm{SOC}_{\max }$ ). There are two actions taken in this operating mode: a) The Inverter continues to be controlled in the same way as in Mode $2 \mathrm{~B}$, so that the maximum permissible power is injected into the Weak Grid $\left(\mathrm{P}_{\text {Grid }}=-\mathrm{P}_{\text {Gridmax }}\right)$. b) The Non-Essential Load is gradually increased; the power consumption increment is proportional to the FB overload with respect to the "maximum" level:

$$
D P_{\text {Load }}=+K\left(S O C-S O C_{m i}\right.
$$

The power capability of the MG modules (that as said before, should be correctly chosen through proper sizing) ensures that, even in the worst case (no power consumption in the Essential Load and maximum renewable generation), with the maximum power consumption of the Essential load and the maximum power injection to the weak grid, the FB stops the overcharging process. The Microgrid will operate in Mode 3B while the FB
SOC complies with $\mathrm{SOC}>=\mathrm{SOC}_{\max }$.

\section{Simulation Results}

To simulate the operation of the Microgrid, covering all possible operation modes, it is required to subject it to working conditions capable to produce a wide variation in the SOC of the FB. Due to the large storage capacity of the FB, this means that the operating time periods must necessarily be long enough. Therefore, for this study, a period of 200 hours is considered.

A Microgrid model has been developed in the Matlab/Simulink environment, where the different modules of the system are represented by simplified subsystems, in order to limit the simulation times. As for the DWIG model, details can be seen in [11]. The model of the photovoltaic module (PV) consists of a power generator, dependent on solar radiation. For FB, a simple model has been used that represents the charging/discharging phenomenon with a goal-oriented approach to the proposed study. The weak grid is modeled by means of ideal voltage sources. Regarding the modeling of electronic power converters, only the fundamental component and/or average value of the associated electrical variable have been represented. The power ratings used in the simulation of the different modules that make up the Microgrid are presented in Table 1.

Table 1. Power ratings of the MG modules.

\begin{tabular}{|l|c|}
\hline \multicolumn{1}{|c|}{ MODULE } & $\begin{array}{c}\text { Power } \\
{[\mathbf{k W}]}\end{array}$ \\
\hline Weak AC Grid & 60 \\
\hline AC Loads (Essential+Non-Essential) & $60+180$ \\
\hline DWIG - PW & 120 \\
\hline DWIG - CW & 60 \\
\hline Solar PV & 100 \\
\hline Storage (FB) & 240 \\
\hline Main Inverter & 240 \\
\hline
\end{tabular}

Fig. 6a shows the wind speed. It was selected to comprehensively cover all the modes of operation of the MG. It is formed by a sinusoidal variation over a constant value of wind speed $(8 \mathrm{~m} / \mathrm{s})$. The amplitude of the variation (peak of $4 \mathrm{~m} / \mathrm{s}$ ) has been chosen so that the DWIG works through the different operating areas (described in section 3A). As for the frequency of this variation, it has been selected considering the highest energy area at low frequencies of the power density spectrum [16]. 
The variation of the DWIG mechanical variables, caused by the wind speed profile, is shown in Fig. 6 . Fig. $6 \mathrm{~b}$ shows the time evolution of the rotor speed in the DWIG, distinguishing two situations: one with a speed almost constant (slightly higher than the nominal, $\omega_{N}=314 \mathrm{rad} / \mathrm{s}$ ) when the PW works, and another with variable speed, lower than the nominal value, when only the $\mathrm{CW}$ is working. Fig. 6c shows the DWIG torque due to the $\mathrm{CW}$, while Fig. 6d corresponds to the PW, and finally, Fig. 6e, the total torque. This figure shows that, with the wind profile considered, the DWIG moves through the three areas of operation described in section 3A. When the DWIG torque is less than approximately $200 \mathrm{Nm}$, it operates in the AB zone of Fig. 3. When it operates with a constant torque close to $200 \mathrm{Nm}$ and the torque due to the $\mathrm{PW}$ is zero, the induction generator operates in the BC zone of Fig. 3. Finally, when the PW comes into action, it means that the wind turbine works in the $\mathrm{CD}$ zone of Fig. 3 and that the rotational speed remains close to its nominal value.
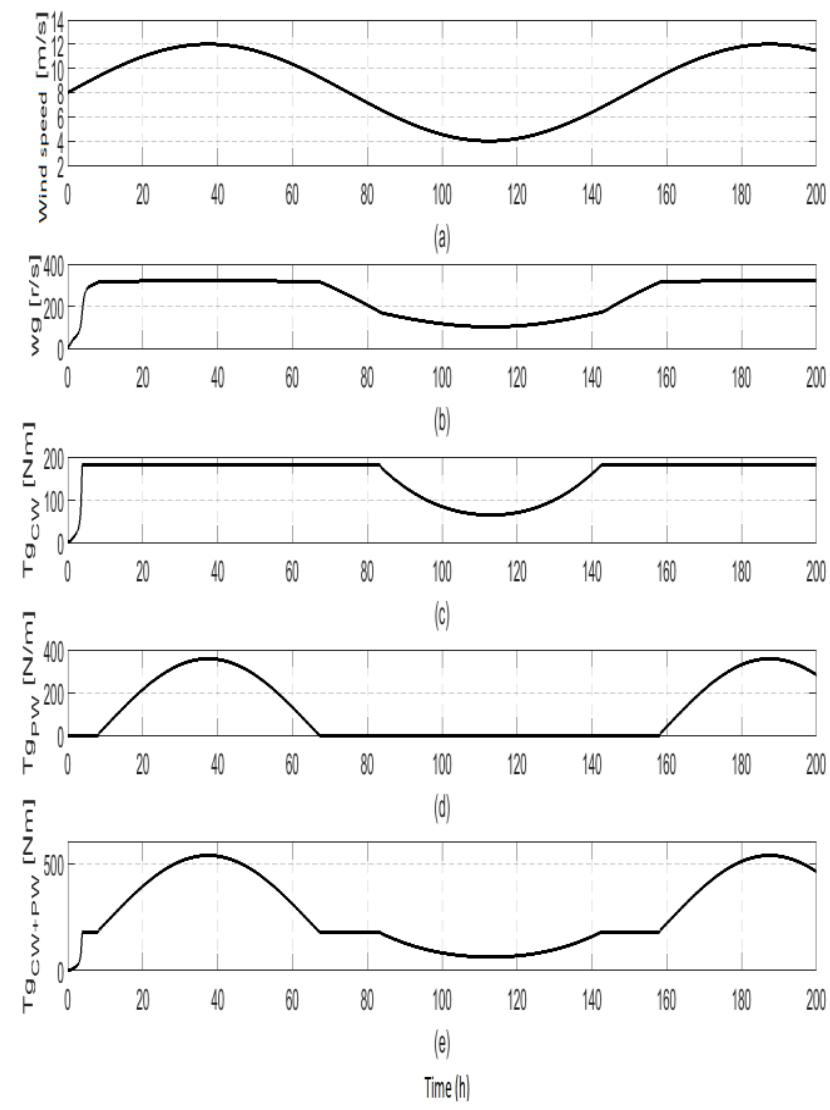

Fig. 6: DWIG torque and rotational speed.

In Fig. 7 it is shown how the Supervisory Control selects the operation mode of the Microgrid based on the SOC of the flow battery, displayed in Fig.7a. If $15 \%<\mathrm{SOC}<85 \%$, the Microgrid operates in Mode 1, (control logic signals: $\mathrm{M} 1=1$ active mode, $\mathrm{M} 1=0$ inactive mode), Fig. $7 \mathrm{~b}$. When $85 \%<\mathrm{SOC}<90 \%$, the Microgrid operates in Mode 2B, Fig. 7c, black control signal. If $\mathrm{SOC}>=90 \%$ the Microgrid operates in Mode 3B, Fig. 7d, control signal in black. If $10 \%<\mathrm{SOC}<15 \%$, the Microgrid operates in Mode 2A, Fig. 7c, control signal in red. If SOC $<=10 \%$, the Microgrid operates in Mode 3A, Fig. 7d, control signal in red.
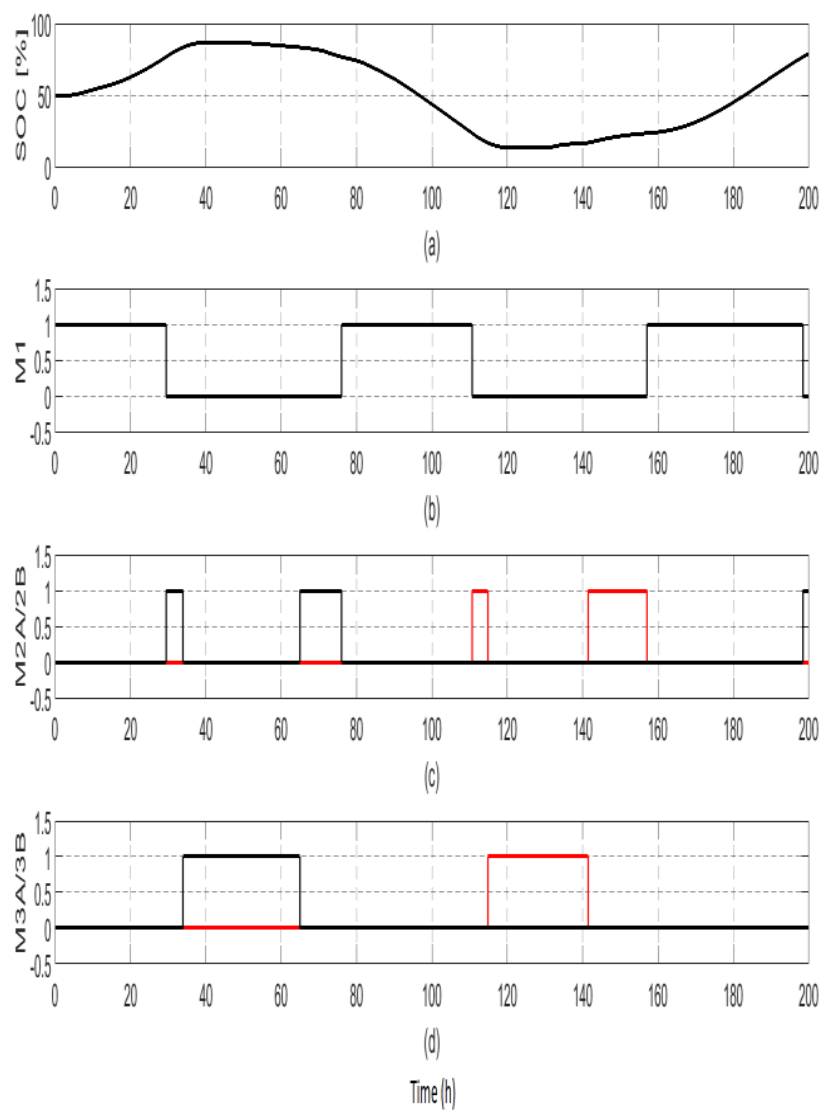

Fig. 7: FB SOC and Supervisory control logic signals.

Fig. 8 shows the power corresponding to the AC bus of the microgrid. First (Fig. 8a), the power supplied by the PW of the DWIG is shown, which is the result of the product of the PW torque and the rotational speed, both already shown in Fig. 6d and Fig. $6 \mathrm{~b}$. The power exchanged with the weak grid is shown in Fig. 8b. It is appreciated that when the system is working on M1 mode, there is no exchange; when it is operating on $\mathrm{M} 2$, the exchange is variable, depending on the SOC of the FB; in M3 the exchanged power remains constant and at its maximum value of $60 \mathrm{~kW}$ (negative when injected into the weak grid, in $\mathrm{M} 2 \mathrm{~B} / \mathrm{M} 3 \mathrm{~B}$ and positive when taken from the weak grid, in M2A/M3A). The control action required to establish the power exchanged with the weak grid is the power of the converter, which is shown in Fig. 8c. The load 
profiles are shown below, the essential in Fig. 8d and the ancillary in Fig. 8e. Note that this last is a "flexible" load, and its control can be adjusted using the monitoring control in mode 3 (increases in M3B and decreases in M3A), Fig. 8f.
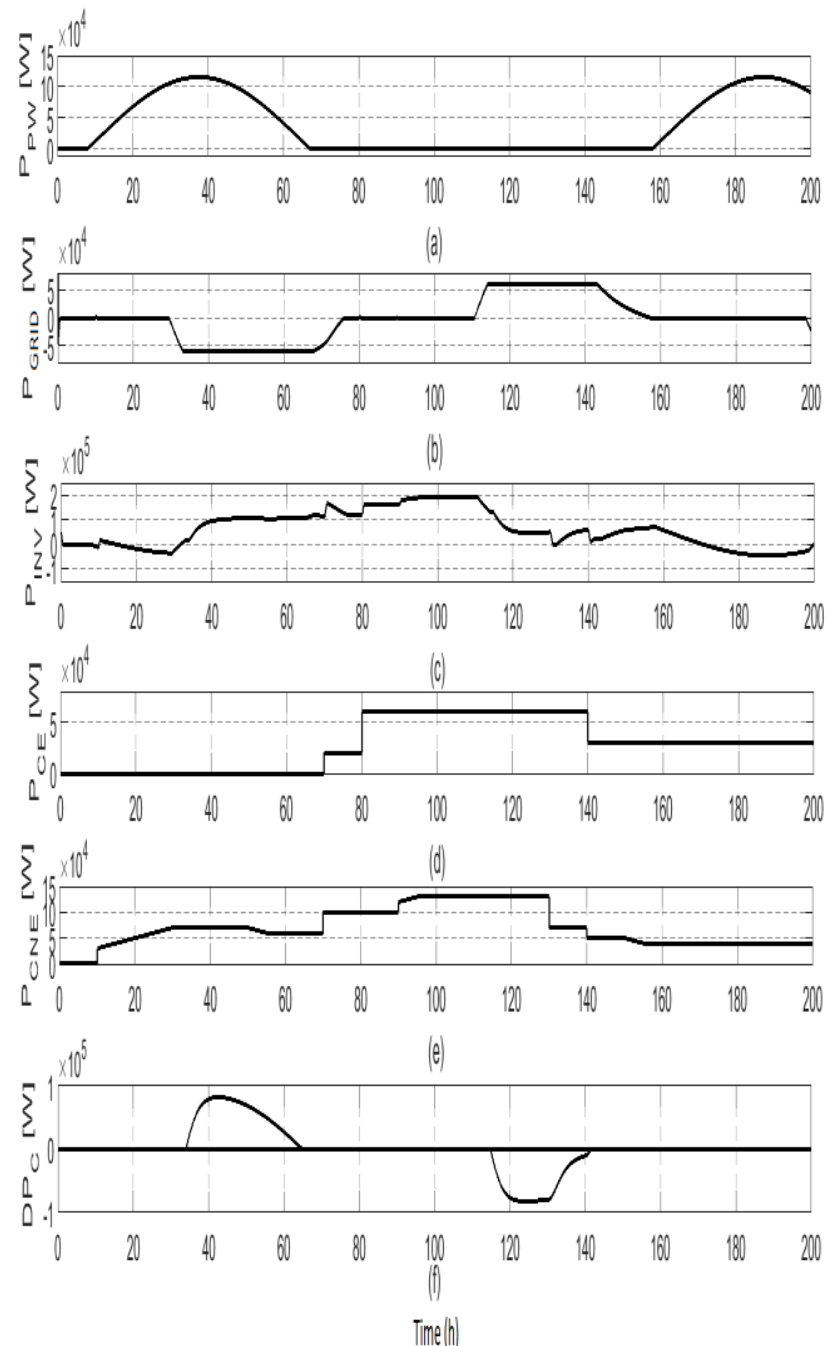

Fig. 8: AC bus powers.

The powers on the DC bus are shown in Fig. 9. Firstly, Fig. 9a displays the power delivered by the $\mathrm{CW}$ of the DWIG, which is the result of the product of the torque of the $\mathrm{CW}$ by the rotation speed of the generator, already shown in Fig. $6 \mathrm{c}$ and Fig. 6b. The power supplied by the PV module is shown in Fig. 9b. The power exchanged between the DC and AC buses (corresponding to the interlinking inverter), can be seen in Fig. 9c. Finally, the power of the storage system (flow battery) is shown in Fig. 9d.

Since only the mean values of the variables are represented in the simulation results, the fast variations of the DC bus voltage are not considered, which would show the operation of the SC. For this reason, the current of the storage system, shown in Fig. 10a, matches the current in the FB. The FB current is controlled to keep the DC bus voltage constant (hence, its shape is very similar to that of the storage power curve, shown in Fig. 9d). The good performance of this control loop is also shown, as the DC bus voltage remains very close to the reference value (1000V), Fig. 10b.
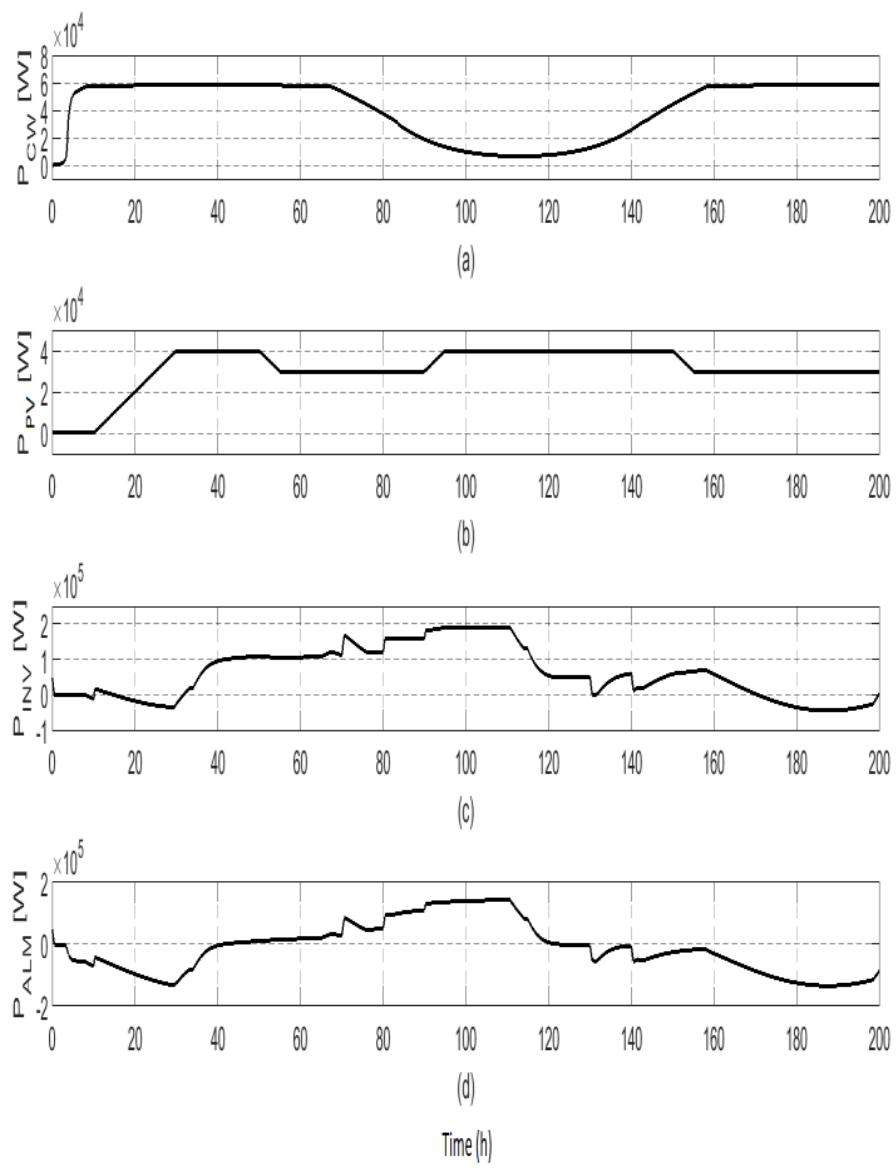

Fig. 9: DC bus powers
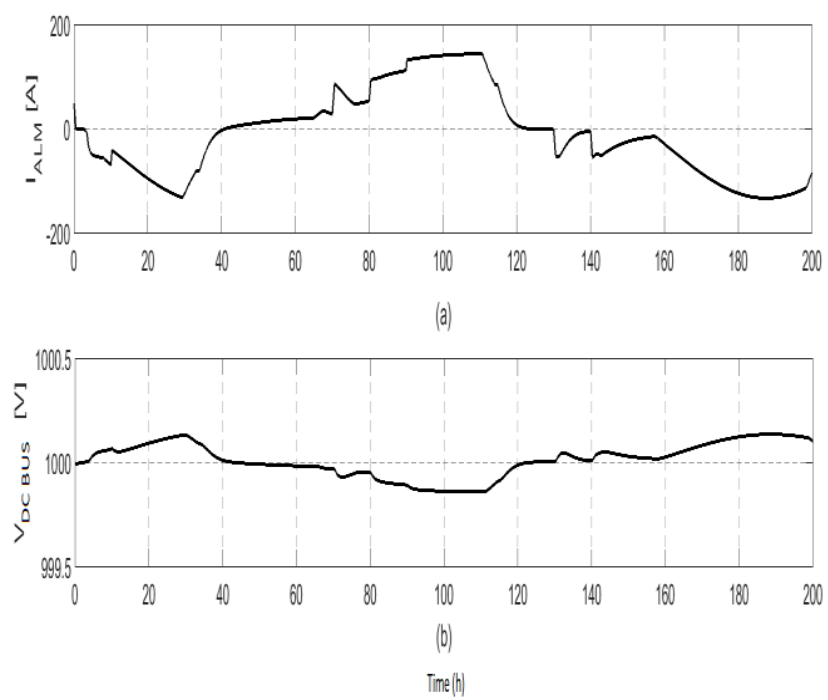

Fig. 10: FB current and DC bus voltage. 


\section{Conclusions}

A sustainable microgrid based on renewable energies and a hybrid storage system has been proposed. Based on a comprehensive simulation analysis, its operation and performance have been assessed, establishing its suitability in the context of distributed renewable generation, connected to a weak line distant from the main $\mathrm{AC}$ grid.

The distinctive features of the proposed wind turbine were a key factor in the structuring of the hybrid configuration of this $\mathrm{AC}+\mathrm{DC}$ microgrid. In fact, based on a DWIG, its dual output enabled connection to the AC and the DC power buses, separately, facilitating the integration the $\mathrm{MG}$ subsystems of different natures. According to the proposed control strategy, with a single wind turbine, it was attained maximum extraction of wind energy, when the resource is scarce, plus direct injection into the $\mathrm{AC}$ grid of a great deal of the wind energy, without requiring another power converter, when the wind is abundant.

This singular wind energy conversion system, combined with a complementary source of solar power and associated to a hybrid storage system based on flow batteries/supercapacitors, gave rise to a highly versatile microgrid for distributed renewable generation. Its most notable features are summarized below:

- Clean and sustainable operation. The integration of renewable energy sources (WT+PV) and a hybrid energy storage systems $(\mathrm{FB}+\mathrm{SC})$, managed through a proficient supervisory control system, provides high-flexibility, adaptability and continuity of power supply to the local loads and grid.

- Enhanced efficiency. By having an AC and a DC bus, the microgrid offers different alternatives to incorporate more generation modules. Depending on the nature of the source, it can be chosen the connection (AC or DC) with fewer conversion stages, hence minor power losses. Moreover, the coupling of the two buses via the interlinking inverter, implies two paths to exchange power with the weak AC grid. This fact offers significant flexibility for the implementation of different modes of operation and a more efficient use of renewable resources and storage devices.

- Inherent fitness of the DWIG-based turbine for AC+DC operation. Due to its especial doublewinding structure, the DWIG proved to be particularly suitable for hybrid microgrids, resulting in a double output wind turbine of reduced maintenance and operating cost. This type of generator has lower cost and smaller size than the classic doubly-fed induction generator. Its squirrel- cage rotor yields a brushless, more robust and reliable machine than the wound rotor case.

- Simplicity to expand the generation and/or storage capacity. The connection of new modules to the DC bus do not require synchronization systems between the electronic converters associated with the different connected sources, unlike what would happen with a single AC bus.

- Minor power exchange with the weak grid. The large storage capacity of the Flow Batteries allows the MG to minimize the energy exchange with the weak grid for a good part of the time.

- Easily rearrangeable to operate in islanding mode. The proposed modular MG could be straightforwardly modified to operate in isolation from the electricity distribution grid, giving that the exchange with the weak grid is limited to a low power value. To this end, a relatively small AC generator set could be incorporated, together with minor modifications to the supervisory control system, to also take care of managing the switching from one mode to the other.

Future work will focus on the design and implementation of highly efficient control systems for the converters, combining robust and adaptive control techniques. Additionally, novel methodologies based on a sliding mode differentiation will be developed to on-line estimate the state of charge and the state of health of the hybrid energy storage system. Also, in the next stage of this research, the analysis and enhancement of the low voltage ride-through capability, together with the protection of different parts of DC side of the microgrid, will be undertaken.

\section{Acknowledgment:}

This work has been sponsored by the UNLP, CONICET and the Agencia I+D+i of Argentina, and by the Spanish Ministry of Science and Innovation under project PID2019-111443RB-100.

\section{References:}

[1] N. Jenkins, J. B. Ekanayake and G Strbac. "Distributed Generation", The Institution of Engineering and Technology 2010.

[2] G. S. Lakshmi, O. Rubanenko, G. Divya and V. Lavanya, "Distribution Energy Generation using Renewable Energy Sources," 2020 IEEE India Council International Subsections Conference (INDISCON), 2020, pp. 108-113, doi: 10.1109/INDISCON50162.2020.00033. 
[3] A. U. Barbosa, B. R. de Almeida, J. S. Guimarães and D. De S. Oliveira, "Distributed generation system using renewable energy sources and a new converter topology," 2016 12th IEEE International Conference on Industry Applications (INDUSCON), 2016, pp. 1-6, doi: 10.1109/INDUSCON.2016.7874583.

[4] Renewables 2021 Status Report, Chapter 4, https://www.ren21.net/gsr2021/chapters/chapter_04/chapter_04/

[5] S. Chowdhury, S. P. Chowdhury and P. Crossley, "Microgrids and Active Distribution Networks", The Institution of Engineering and Technology 2010.

[6] D.J. Hammerstrom, "AC versus DC distribution systems: did we get it right?", IEEE Power and Energy Soc. General Meeting, 2007, pp. 1-5.

[7] Asad R, Kazemi A., "A quantitative analysis of effects of transition from ac to dc system, on storage and distribution systems: smart grid technologies", IEEE PES Asia-Pacific power and energy engineering conference (APPEEC); 2012, p.1-5.

[8] A. Gupta, S. Doolla, K. Chatterjee, "Hybrid AC-DC Microgrid: Systematic Evaluation of Control Strategies", IEEE Trans Smart Grid, Vol. 9, No. 4, July 2018, pp. 3830-3843.

[9] Badal, F.R., Das, P., Sarker, S.K. et al. A survey on control issues in renewable energy integration and microgrid. Prot Control Mod Power Syst 4, 8 (2019). https://doi.org/10.1186/s41601-019-0122-8.

[10] D. Zhou, S. Chen, H. Wang, M. Guan, L. Zhou, J. $\mathrm{Wu}, \mathrm{Y}$. $\mathrm{Hu}$, "Autonomous Cooperative Control for Hybrid AC/DC Microgrids Considering Multi-Energy Complementarity", Frontiers in Energy Research, 2021. DOI: 10.3389/fenrg.2021.692026.

[11] Bu, F.; Liu, H.; Huang, W.; Xu, H.; Hu, Y. "Recent advances and developments in dual stator winding induction generator and system", IEEE Trans. Energy Convers. 2018, 33, 1431-1442.

[12] Barrado J. A, Munté Puig X., ValderramaBlavi H., Guasch-Pesquer L. "Implementation, modelling and performance analysis of a dual stator-winding induction generator", International Journal of Computations and Mathematics in Electrical (COMPEL), Vol. 32, No. 1, pp. 302-312, 2013.

[13] L. Joerissen, J. Garche, Ch. Fabjan, G Tomazic "Possible use of vanadium redox-flow batteries for energy storage in small grids and stand- alone photovoltaic systems". Journal of Power Sources, 127, pp 98-104, 2004.

[14] J.J. Moré, P.F. Puleston, C. Kunusch, M. Allue Fantova "Development and Implementation of a Supervisor Strategy and Sliding Mode Control Setup for Fuel Cell-Based Hybrid Generation Systems". IEEE Trans Energy Conversion (ISSN 0885-8969). Vol. 30, Issue 1, pp. 218-225, March 2015.

[15] J.I. Talpone, P.F. Puleston, M.G. Cendoya, J.A. Barrado-Rodrigo, "A Dual-Stator Winding Induction Generator Based Wind-Turbine Controlled via Super-Twisting Sliding Mode", Energies. Vol. 12, Iss. 23, pp. 4478 (20), 2019. DOI: $10.3390 / \mathrm{en} 12234478$

[16] C. Gavriluta, S. Spataru, I. Mosincat, C. Citro, I. Candela, P. Rodriguez, "Complete methodology on generating realistic wind speed profiles based on measurements", RE\&PQJ, Vol.1, No.10, April 2012.

\section{Creative Commons Attribution License 4.0 (Attribution 4.0 International, CC BY 4.0)}

This article is published under the terms of the Creative Commons Attribution License 4.0 https://creativecommons.org/licenses/by/4.0/deed.en US 